\title{
Experience and further development with the Voluntary Harmonization Procedure for multinational clinical trials in the European Union
}

\author{
Hartmut Krafft, Chantal Bélorgey and Gudrun Szalay
}

In their recent correspondence related to an interview discussing the Voluntary Harmonization Procedure (VHP) for the assessment of multinational clinical trials in the European Union (EU) (An audience with... Hartmut Krafft. Nature Rev. Drug Discov. 9, 426 (2010)) $)^{1}$, Amexis and Schmitt discussed their experience of the VHP from their perspective as trial sponsors (A sponsor's experience with the Voluntary Harmonization Procedure for clinical trial applications in the European Union. Nature Rev. Drug Discov. 10, 393 (2011)) $)^{2}$. The VHP was established by the Clinical Trials Facilitation Group in 2004 to address difficulties arising from the implementation of the EU Clinical Trials Directive ${ }^{3}$ into national laws and regulations, which led to divergent review processes for clinical trial applications in the member states. Here, as representatives of the Clinical Trials Facilitation Group, we summarize the experience so far with the VHP, including data on usage, and highlight further developments.

The main advantage of the VHP is that the assessment of a multinational clinical trial application (MCTA) by the relevant member states is done in a coordinated way.

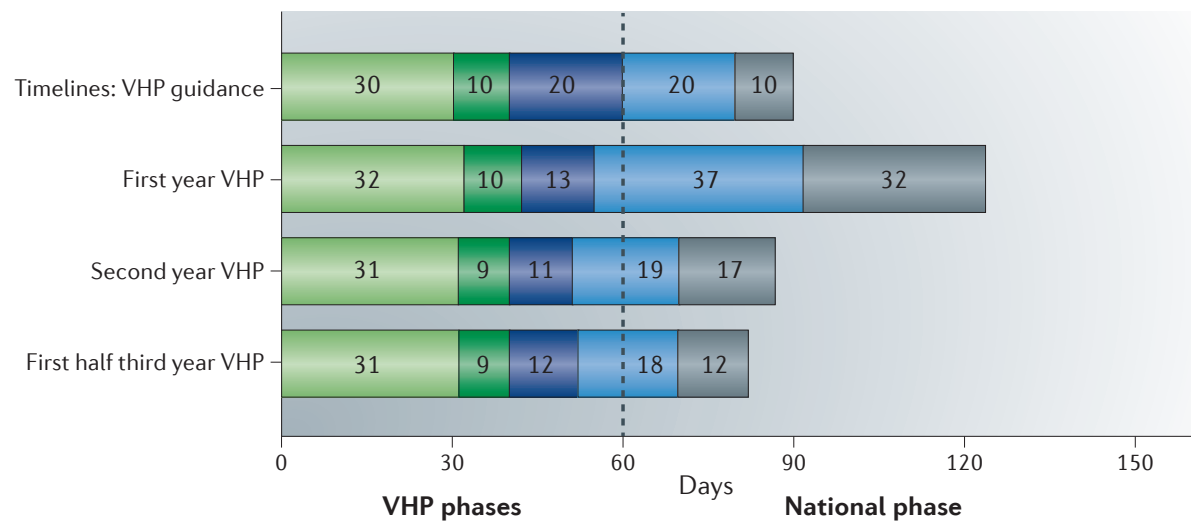

\begin{tabular}{|ll|}
\hline Time for VHP assessment and consolidation & $\square$ Time for national application \\
$\square$ Time response to GNA & $\square$ Time for national authorization \\
$\square$ Time for VHP assessment &
\end{tabular}

Figure 1 | Time taken to get approval of a multinational clinical trial through the Voluntary Harmonization Procedure (VHP). GNA, grounds for non-acceptance. in which the general documents are scientifically assessed, and no further member-statespecific modifications of general documents are necessary. With the implementation of VHP version 2 from March 2010, a few new features have also been introduced ${ }^{4}$. For example, all clinical trials with three member states can be applied for, assessment is coordinated by a leading member state, and application for substantial amendments is also possible.

The VHP has received increasing acceptance since its introduction in 2009. From March 2009 to 1 February 2012, 144 applications were received in total, comprising 133 standard VHPs and 11 accelerated VHPs owing to the pandemic influenza vaccines. TABLE 1 illustrates the different phases that the MCTAs were filed for, and their outcome. All phases of a clinical trial have been considered, and more than $90 \%$ of the MCTAs received a positive opinion. Of the VHP applicants, $86 \%$ are commercial and $14 \%$ are non-commercial. The greatest acceptance of the VHP by sponsors came from the United States (47), Switzerland (18), Germany (15), the United Kingdom (14) and Belgium (13). Sponsors from France, Austria, Italy, Sweden, Denmark and the Netherlands have also participated in the VHP. The nature of the investigational medicinal products is approximately equally distributed between chemical entities and biologics.

Concerning the member states chosen by sponsors for multinational clinical trials, out of the $27 \mathrm{EU}$ members and 5 European Economic Area countries, 22 member states have joined the VHP. Within this group, Germany, France and Spain have participated in at least every second application. So far, only a few countries have not been selected for a VHP, including Malta, Cyprus, Luxembourg, Slovenia and Liechtenstein. Currently, Poland cannot participate owing to lack of a legal basis. The average number of member states selected for a VHP and finally participating in the assessment is 6 , with a range from 2 to 14 per application.

With version 2 of the VHP guidance, one of the biggest improvements was the implementation of an internal leading member state, whose task is to consolidate the list of questions of the single member state arising during assessment, thereby avoiding redundancy of questions. This resulted in an average reduction of initial questions by around 50\% before they were sent to the applicant.

The main benefit of the VHP is the reduction in time for the approval of the MCTA, which is demonstrated by the data in FIG. 1 The time taken to get a VHP opinion is a 


\begin{tabular}{|c|c|c|c|c|c|c|}
\hline Phase/opinion & FIH & I & II & III & IV & $\Sigma$ \\
\hline Positive & 2 & 3 & 38 & 46 & 4 & 93 \\
\hline Negative* & 1 & 1 & 0 & 3 & 0 & 5 \\
\hline Divergent $^{\ddagger}$ & 0 & 0 & 1 & 5 & 0 & 6 \\
\hline Withdrawn & 1 & 0 & 1 & 6 & 0 & 8 \\
\hline Open & 2 & 1 & 8 & 10 & 0 & 21 \\
\hline
\end{tabular}

FIH, first in human; VHP, Voluntary Harmonization Procedure. *If grounds for non-acceptance had not been sufficiently answered. If only a single participating member state required additional changes to be able to approve the national application.

maximum of 60 days (which also comprises the 10 days of sponsor's time to resolve grounds for non-acceptance) preceded by a 5 -day validation. Subsequent national approval is achieved within 10 days, after the applicant has had 20 days to submit a valid application to the national competent authorities (NCAs). The experience with the VHP so far is that timelines for the VHP are met or even reduced. In the first year following the introduction of the VHP the national step was time-consuming for both the sponsor and the NCAs, but in the third year $10 \%$ less time than scheduled was needed for an MCTA approval (FIG. 1).

Further improvements for the VHP came into force in September 2011. First, the assessment of an MCTA has been further improved. The leading member state is now replaced by a reference-NCA with the possibility to introduce a co-reference NCA, depending on the nature of the investigational medicinal product. The other participating NCAs receive the preliminary assessment report, and can decide on this basis whether they agree or whether they have additional grounds for non-acceptance to produce a more stringent list of such grounds and use resources more efficiently. The second alteration is the possibility to have a second round of a VHP to add additional member states in an already approved VHP. Timelines for the second round are, in principle, the same as in the first round. However, as the assessment report from the first round is adopted, assessment by the new member states might speed up and approval might be quicker. Overall, these improvements should save further time for applicants.

Hartmut Krafft and Gudrun Szalay are at the Paul-Ehrlich Institut, Paul-Ehrlich Straße 51-55, 63225 Langen, Germany.

Chantal Bélorgey is at the Department of Evaluation of Clinical Trials and Special Status Medicinal Products, Afssaps, Direction de l'Evaluation des Médicaments et des Produits Biologiques, 143/147 Boulevard Anatole France, 93285 Saint-Denis Cedex, France.

Correspondence to H.K. e-mail: $\underline{\text { Hartmut.Krafft@pei.de }}$ doi: 10.1038/nrd3202-c2 Published online 10 April 2012

1. Hughes, B. An audience with... Hartmut Krafft. Nature Rev. Drug Discov. 9, 426 (2010).

2. Amexis, G. \& Schmitt, E. A sponsor's experience with the Voluntary Harmonization Procedure for clinical trial applications in the European Union. Nature Rev. Drug Discov. 10, 393 (2011).

3. European Commission. Directive 2001/20/EC European Commission website [online], http://eur-lex. europa.eu/LexUriServ/LexUriServ.do? uri = CONSLEG: 2001L0020:20090807:EN:PDF (2001).

4. Heads of Medicines Agencies (HMA). Guidance document for a Voluntary Harmonisation Procedure (VHP) for the assessment of multinational Clinical Trial Applications: version 2. HMA website [online], http://www.hma.eu/fileadmin/dateien/Human Medicines/01-About_HMA/Working_Groups/ CTFG/2010 03 VHP Guidance_v2.pdf (2010).

\section{Acknowledgements}

We thank all the participating member states and the Heads of Medicines Agencies (HMA) for their constant support of the Voluntary Harmonization Procedure (VHP), as well as W. Kannegiesser for expert coordination. 